\title{
Cenas do testemunho na televisão: o (des)encontro de mundos
}

Leandro Rodrigues Lage

Resumo: Busca-se compreender como o testemunho midiático pode ser concebido como ação potencialmente política, isto é, em sua capacidade de produzir cenas polêmicas e de evidenciar simultaneamente um comum partilhado e uma separação. Tal movimento é fortemente inspirado na perspectiva política de Rancière. Nesse sentido, analisa-se a narrativa sobre o cotidiano do jovem viciado Paulo "Treze", contada no programa televisivo A Liga, como evidência da coexistência e da contradição de mundos instaurada pelo testemunho midiático.

Palavras-chave: testemunho midiático; televisão; narrativa.

Abstract: Scenes of testimony on television: the (non)encounter of worlds - This paper seek to understand how the media testimony can be conceived as a potentially political action in its ability of producing controversial scenes and simultaneously demonstrating a shared common and a separation. Such movement is inspired by the J. Rancière's political perspective. In this sense, we analyze the narrative about the daily routine of the young addict Paul "Thirteen" as told in the television show A Liga, or the Team as an evidence of the coexistence and contradiction of worlds established by the media testimony.

Keywords: media testimony; television; narrative.

\section{Primeira cena:}

Paulo "Treze" e o jornalista Rafinha Bastos estão sentados na calçada, recostados em um muro pichado. "Treze" fuma um cigarro e aparenta irritação. A tomada de imagens é feita do outro lado da rua. Rafinha pergunta: "-Quando você fica chateado assim você lembra o quê? Lembra tua família, cara?" "Treze" responde, com lágrimas nos olhos: -"Dá saudade, né, velho? [...] Isso daí não é vida para ninguém, ó nego. É que usuário é foda, né, velho? O bagulho vicia, é gostoso, é da hora. Eu quero acabar a reportagem fumando umas dez, vinte, cem pedras. Fumar até um quilo. Até morrer de fumar, velho". 


\section{Segunda cena:}

Após momentos de tensão e nervosismo em que "Treze", depois de interromper pela segunda vez a filmagem para comprar crack, conta ao repórter que acabara de ser ameaçado pelos traficantes por ter "dedurado a boca", Rafinha aparece sentado, sozinho, em uma área verde. O repórter, ainda na metade da jornada de um usuário que se propôs acompanhar, começa a desabafar com a câmera, sem olhá-la diretamente: "-Eu não sei se a gente teria a função, nesse caso, de fazer alguma coisa, de ajudar, sem soar muito demagógico. Eu sei que esse menino precisa de ajuda, cara. Esse menino precisa de ajuda, urgentemente".

\section{Terceira cena:}

É noite. "Treze" leva o repórter até o lugar onde costuma fumar o crack. É a quarta vez que consome a droga durante a reportagem. Os dois aparecem sentados sob uma árvore. A cor da imagem se alterna entre o esverdeado da "função noturna" da câmera e escuridão quase total. "Treze" traga o cigarro de crack diante da câmera. Rafinha aguarda quieto. Depois de baforar, "Treze" exclama: "- Que delícia, ó! Que da hora! Infelizmente, que da hora!". Rafinha, então, pergunta: "- Se oferecem para você ter sua família te apoiando, te dando emprego, uma vida diferente, e esse cigarro aí, você hoje escolhe o quê?", "Treze" é enfático: "- Posso fumar? Entendeu? Entendeu? Então já é!".

\section{Introdução}

A história de Paulo "Treze", usuário de crack de 22 anos, foi contada no programa televisivo A Liga, exibido pela Rede Bandeirantes desde 2010. Naquela reportagem, ao mesmo tempo que "Treze" presta testemunho sobre o próprio vício, o jornalista que o acompanha testemunha de perto seu infortúnio, e nós, espectadores, também nos tornamos testemunha daquele sofrimento televisionado.

Mas por que somos apresentados à desgraça de "Treze"? Ele é apenas um sujeito qualquer, cuja imagem e palavra não significam mais do que ruído, não expressam mais do que sofrimento? Podemos dizer que "Treze" ocupa, naquela história, um espaço de visibilidade e dizibilidade? A proposta deste trabalho é, precisamente, operar uma inflexão entre essas indagações, na tentativa de compreender como o testemunho midiático pode ser concebido como ação potencialmente política capaz de reconfigurar a ordem do sensível.

O testemunho midiático vem sendo investigado por autores da comunicação desde a última década, num interesse motivado em grande parte pelos estudos sobre o acontecimento midiático, que, por sua vez, ganharam impulso no pós-11 de Setembro. A noção passou figurar em outras áreas de conhecimento, como na comunicação, ajudando 
a compreender outros processos, ampliando, ao mesmo tempo, o horizonte de problemas (ASHURI; PINCHEVSKY, 2009; FROSH, 2009 e FROSH; PINCHEVSKI, 2009).

Nesse sentido, uma primeira compreensão do testemunho midiático implica uma simples conjunção: "'testemunho midiático' é o testemunho performado na, pela e através da mídia" (FROSH; PINCHEVSKI, 2009, p. 1; grifo dos autores, tradução nossa $)^{1}$. Ou seja, tal modalidade de testemunho se refere, simultaneamente, às testemunhas enredadas nos relatos da mídia, tal como "Treze"; refere-se ao entendimento de que as próprias mídias testemunham, como o programa o faz a partir da figura do jornalista que acompanha aquele usuário de crack em sua jornada diária; e, por fim, refere-se à nossa condição de testemunha enquanto espectadores.

A discussão sobre o testemunho midiático torna fundamental o problema da presença, principalmente no sentido de autorizar a testemunha a prestar depoimento sobre a experiência vivida (PEETERS, 2009). Mas a preocupação com a presença à maneira de um mecanismo de atestação da realidade narrada midiaticamente permanece restrita ao entendimento do testemunho como estratégia retórica do jornalismo, obliterando o que autores apontam ser o moral point do testemunho midiático, a saber, a possibilidade de encontro com o outro. Nesse sentido, o testemunho midiático cria um espaço comum através do qual reconhecemos o outro como igualmente humano e, ao mesmo tempo, interpõe uma distância espacial e temporal entre nós e esse outro (FROSH, 2009).

O caráter relacional do testemunho - que requer alguém que dê testemunho em interação com outrem que o leia, escute ou veja - leva-nos a pensá-lo como modo de ocupação e organização do sensível, no sentido em que evidenciaria a relação entre uma comunhão e uma separação, entre uma proximidade e uma distância. O conceito de "partilha do sensível" foi cunhado pelo filósofo Rancière (1995; 1996; 2004 e 2005) para designar a existência de evidências sensíveis que dão a ver um comum partilhado e a divisão de partes exclusivas que constituem a comunidade. "Essa repartição das partes e dos lugares se funda numa partilha de espaços, tempos e tipos de atividade que determina propriamente a maneira como um comum se presta à participação e como uns e outros tomam parte nessa partilha" (RANCIÈRE, 2005, p. 15).

O conceito de partilha do sensível constitui a base argumentativa de Rancière para sua própria definição de política, que diz respeito sobretudo à ruptura de uma certa configuração do sensível, isto é, a uma forma de tornar evidente a divisão dos modos e capacidades de fazer, aparecer e dizer, bem como a distribuição dos corpos na ordem sensível segundo funções, tempos e lugares específicos.

Diante da necessidade de desenvolver essa abordagem, optaremos por não defender antecipadamente um caráter político do testemunho midiático. Em vez disso, inspirados em Rancière, tomaremos emprestada sua gramática utilizada para abordar a política e sua gênese estética, para assim percebermos o testemunho em sua capacidade de produzir cenas polêmicas, isto é, de evidenciar simultaneamente um comum partilhado e uma separação.

1 "'media witnessing' is the witnessing performed in, by, and through the media" 


\section{Ocupações do sensível}

Para Rancière, uma ordem política é, desde sempre, uma configuração do sensível. O filósofo francês desenvolve uma abordagem da política voltada não apenas para o jogo argumentativo que tradicionalmente a define, mas principalmente para as dimensões estética e política que regulam tanto o que é dito e por quem quanto as próprias condições de dizibilidade e de visibilidade. Estética, nesse sentido, "é o que revela a presença de mundos dissenssuais dentro de mundos consensuais, evidenciando as tensões que constituem a política como forma de experiência" (MARQUES, 2011, p. 33). E a política passa a dizer respeito, sobretudo, ao conflito em torno da ocupação do sensível, isto é, do litígio sobre a existência de uma cena comum.

Nessa concepção de política, os argumentos dão lugar a um problema anterior, acerca do próprio lugar dos sujeitos enquanto seres de palavra - em oposição à condição de seres capazes apenas de produzir ruído. Trata-se de uma ordem sensível na qual estão em jogo inclusive as condições de aparição dos sujeitos ante uma distribuição desigualitária dos corpos.

Para Rancière, essa constituição estética, sob a forma de uma partilha da ordem do sensível, é o que dá forma à comunidade. "Partilha significa duas coisas: a participação em um conjunto comum e, inversamente, a separação, a distribuição dos quinhões" (1995, p. 7). O cerne da política é estético porque opera segundo uma partilha, uma organização do que é visível, dizível e, portanto, do que se constitui como possível.

Em contraposição declarada ao modelo político habermasiano, fortemente ancorado no plano argumentativo-racional, Rancière defende um caráter dissensual da política, cuja lógica está menos relacionada à busca de um consenso e mais atenta a uma suposta igualdade entre os indivíduos que deve ser posta à prova constantemente. Para o filósofo, a política se efetua precisamente porque uma mesma comunidade abriga sempre duas parcelas: a dos contados e a dos que não são contados. É nesse sentido que opera o dano, isto é, o desvelamento de uma conta mal feita, de um desequilíbrio na medida do comum.

Existe política porque aqueles que não têm direito de ser contados como seres falantes conseguem ser contados, e instituem uma comunidade pelo fato de colocarem em comum o dano que nada mais é que o próprio enfrentamento, a contradição de dois mundos alojados num só: o mundo em que estão e aquele em que não estão, o mundo onde há algo "entre" eles e aqueles que não os conhecem como seres falantes e contáveis e o mundo onde não há nada. (RANCIÈRE, 1996, p. 40)

O valor dessa abordagem política ainda é a igualdade, mas não como pressuposto, e sim como um "universal singular", no sentido de que é um valor sujeito à verificação em cada episódio, sendo exercido na singularidade. A inferência retirada por Rancière desse pressuposto é, como o diz o próprio autor, desconcertante: “Deduz-se daí, em suma, 
que a desigualdade dos níveis sociais só funciona por causa da própria igualdade dos seres falantes" (ibid., p. 60). Trata-se de argumentar que a igualdade assume a figura política porque é, ela mesma, instauradora de uma totalidade excludente, de um comum cindido.

Nesse sentido, os episódios dessa política existem sob a forma da demonstração dessa contradição de mundos que constitui a comunidade, através da constituição de cenas de dissenso. Para Rancière (ibid., p. 66), "a demonstração própria da política é sempre, a um só tempo, argumentação e abertura do mundo no qual a argumentação pode ser recebida e fazer efeito, argumentação sobre a própria existência desse mundo".

Quando faz referência ao comum de uma comunidade, Rancière chama atenção para a contradição, para a divisão do sensível na qual estão encaixadas as partes contadas e não contadas, que merecem passar por uma verificação polêmica cuja consequência maior é a própria reorganização da ordem do sensível.

\begin{abstract}
A afirmação de um mundo comum efetua-se assim numa encenação paradoxal que coloca juntas a comunidade e a não-comunidade. E uma tal conjunção remete sempre ao paradoxo e ao escândalo que perturba as situações legítimas de comunicação, as divisões legítimas dos mundos e das linguagens, e redistribui a maneira como os corpos falantes estão distribuídos numa articulação entre a ordem do dizer, a ordem do fazer e a ordem do ser (RANCIÈRE, 1996, p. 66).
\end{abstract}

É essa encenação paradoxal capaz de romper a configuração sensível na qual estão distribuídas as partes contadas e não contadas que nos interessa, porque é reveladora dessa abordagem da política sob a forma do encontro polêmico entre dois processos heterogêneos, uma ordem sensível consensual e uma ordem sensível contraditória, através de um encontro dissensual de mundos.

Para Rancière, é somente sob a forma da tomada da palavra e da ocupação do sensível que pode haver uma "mise-en-acte de l'égalité", isto é, uma manifestação do justo através do exercício efetivo da igualdade de condições. Essa demonstração do dano, da contradição de dois mundos alojados num só, é a própria constituição do comum que não preexistia, um comum no qual está em jogo a igualdade dos sujeitos, no qual está em jogo a própria aparição e pertinência dos sujeitos para o mundo. E tal demonstração se dá pela linguagem, em ações e encenações perturbadoras das divisões legítimas dos mundos.

A potência desses episódios da política, ou dessas cenas polêmicas dissensuais instituídas no campo das ações, residiria na capacidade de reconfiguração da ordem do sensível, permitindo novas inscrições dos sujeitos a partir de uma abertura das esferas de visibilidade e de dizibilidade, tornando manifesta a igualdade dos sujeitos falantes e a desigualdade das condições de fala. É-nos interessante pensar a constituição dessas cenas polêmicas porque, pela via da demonstração sob a forma de encenações, de representações, elas abrem a possibilidade de vislumbrarmos na prática esse encontro de mundos dissensuais e que, no entanto, coabitam uma ordem do sensível muitas vezes sob a forma de um consenso tácito - porque nunca posto à prova. Como ressalta Marques: 
Eis aqui uma questão central: a comunidade de partilha opõe um espaço consensual a um espaço polêmico, ela faz aparecer sujeitos que até então não eram contados ou considerados como interlocutores, traz à experiência sensível vozes, corpos e testemunhos que até então não eram vistos como dignos de respeito e estima (2011, p. 34).

É essa entrada de vozes, corpos e testemunhos no campo da experiência sensível que nos permite pensar de maneira concreta as formas de constituição das cenas polêmicas, tensionando ao mesmo tempo sua capacidade de provocar rupturas na ordem do discurso e na ordem do sensível. Isso porque lançar mão da gramática rancieriana tentando observar os testemunhos relativos à ordem discursiva midiática nos impõe, de saída, a própria contradição entre uma configuração sensível e discursiva altamente sobredeterminada (roteirizada, planejada e controlada) e as possibilidades de abertura. Por outro lado, reivindicando não apenas as relações de poder preexistentes, mas a própria possibilidade de encontro de mundos, acreditamos ser possível operar um esforço compreensivo em direção ao testemunho midiático a partir do substrato da ideia de constituição de cenas dissensuais.

Em suma, o que pretendemos é tirar consequências do entendimento de que o testemunho midiático detém a capacidade de constituir "um espaço comum através do qual reconhecemos o outro como igualmente humano" a partir do quadro conceitual desenhado por Rancière para pensar a política como prática de uma verificação polêmica, como evidência do caráter dissensual do comum de uma comunidade. Para tanto, a narrativa sobre o cotidiano do jovem viciado Paulo "Treze", contada no programa televisivo A Liga, parece-nos exemplar naquilo que revela acerca da contradição de mundos: o mundo da enunciação midiática, o de Paulo "Treze" e o dos espectadores.

As cenas que descrevemos no preâmbulo mostram que a inexistência de "Treze" se torna manifesta e expressiva naquela história, mas seria a fala do personagem uma fala, e não ruído? "Treze" exerce e ocupa o lugar de um sujeito singular, e não o da figura prototípica do adicto? A sua aparição e sua fala, no arranjo das imagens televisivas, são capazes de sugerir uma reorganização do sensível? Em que medida podemos tratar aquela cena de testemunho à maneira de uma cena polêmica em que o mundo de "Treze" invade ou se coaduna ao mundo do espectador?

\section{"Treze" e a cena do testemunho}

Pode-se interpretar a reportagem de $A$ Liga como forte evidência da intrusão jornalística no sofrimento alheio, ou do quanto o programa trabalha sob uma ordem do olhar, do espreitar, que preside a aparição do outro sem lhe conceder efetivamente a palavra. Como diz o próprio Rancière (2010) sobre os regimes de visibilidade e dizibilidade das imagens televisivas, se o horror se banaliza nessas telas, não é porque vemos imagens em excesso de corpos sofredores. "Mas vemos demasiados corpos 
sem nome, demasiados corpos incapazes de nos devolver o olhar que lhes dirigimos, demasiados corpos que são objeto da palavra sem ter, eles mesmos, a palavra" (ibid., p. 97; tradução nossa).

Por outro lado, talvez seja possível denegarmos temporariamente a organização discursiva que rege as condições de aparição de Paulo "Treze" e nos deixarmos levar pelas possibilidades abertas por aquela narrativa, tentando ver além dessa condição opressora e invasiva relativa ao exercício do controle e do poder.

A própria constituição do programa $A$ Liga oferece uma alternativa em relação às fortes convenções jornalísticas relativas, por exemplo, às estratégias de apagamento da instância narrativa como operação de mediação - tão bem comentadas por Eco (1984) em seu ensaio sobre a "transparência perdida".

Em suas reportagens, A Liga tenta promover uma imersão dos jornalistas-narradores no mundo por eles retratado - e, ao mesmo tempo e consequentemente, promove uma forma de imersão dos espectadores nesse mundo. É certo que também a incursão dos jornalistas em determinados mundos constitui estratégia de autenticação da realidade configurada narrativamente.

Entretanto, o que nos interessa são menos os mecanismos dos quais A Liga lança mão para construir suas reportagens, segundo os postulados deontológicos jornalísticos, do que as consequências dessas estratégias para a compreensão do testemunho midiático como possibilidade de encontro entre mundos distintos.

O protagonista da história sob o escrutínio é o jovem Paulo "Treze", que logo é apresentado ao espectador como um viciado, um sujeito totalmente entregue às drogas. Sua primeira aparição é a uma distância segura: jogado no chão do pátio de uma construção abandonada, ao lado de um campo de futebol, ele é acordado pelo repórter, que troca cumprimentos e anuncia que está lá para acompanhá-lo em sua jornada diária de busca pelo crack, o "corre" - aparentemente confirmando um acerto prévio entre ambos. "Treze" não foge à filmagem. Talvez porque não se deixe necessariamente dominar por ela, ou ache que não se deixa, ou mesmo porque não tem medo de se deixar dominar. Certamente sabe o que é ser filmado, mas, sob o efeito constante da droga, não sabemos se tem consciência do que isso significa.

A despeito da desigualdade que regula aquela narrativa, com offs e passagens que revelam a quem pertence a palavra sobre o que é mostrado, não podemos negar que a tomada de imagem seja também uma tomada de linguagem. "Treze" ocupa aquela cena com veemência. Toma a palavra e, em determinados momentos, chega a ditar o caminho que é seguido pela reportagem, ora pelas ruas do distrito paulistano de Brasilândia, ora por terrenos baldios e construções abandonadas onde consome a droga. Em uma das cenas mais expressivas daquela edição do programa, sua caminhada é interrompida por um homem cujo rosto não foi identificado, que interpela o protagonista sobre o risco que a filmagem traz para a "biqueira" onde é vendida a droga: 
- Você sabe que ainda vai dar pano para rolar essa fita aí, né, tio? Você quer passar sua caminhada para os cara, rola pra lá. Você não tem nem que tá com os caras aqui pra baixo, aqui. Você tá ligado como é que funciona o baguio.

Rafinha Bastos, então, volta-se para "Treze" e pergunta: - Você quer não ir pra lá e ir para outro lugar? Vai num lugar que é mais seguro pra você, velho.

O homem avisa novamente: - Você pode esperar que isso daí ainda var dar pano pra manga e você sabe disso.

Rafinha insiste para "Treze": — Você tá vendo? Não vamo lá, vai.

Ao que "Treze" responde: - Então vamo lá pro cemitério.

Após um corte, Rafinha Bastos aparece de braços cruzados, sem reação. "Treze" continua inquieto, e o homem já não aparece na cena. Aparentemente, está ao lado da câmera. E diz:

- Você está na periferia. Aqui tem coisas boas, mas tem baguio errado. Ai cê vai colocar os caras pra filmar aqui. Não é nada contra os caras, não, porque os caras tão fazendo o serviço deles, certo? Eu tô ligado que os caras não são ganso.

"Treze" responde: - Eu vou fumar lá no cemitério, então. Não vou fumar ali no meio do campo perto das crianças.

— Mas você não é nem louco. Não era nem pra você tá sentado ali.

O homem aparentemente vai embora e "Treze", ao lado de Rafinha, vira e o chama: - Vamo!

Na cena seguinte, Rafinha Bastos aparece constatando para a câmera que, até então, estivera filmando com tranquilidade, inclusive nos locais onde havia grande consumo da droga. Segundo o jornalista, a ameaça do homem aparentemente envolvido com o tráfico na região revelou uma insegurança, própria do mundo de "Treze", da qual ele, o repórter, não tinha se dado conta. O depoimento é cortado e, em seguida, mostra-se o retorno do personagem, que chega anunciando que precisa voltar para terminar o trabalho para o qual fora contratado no início da reportagem - uma das formas de conseguir dinheiro para comprar crack é trabalhando como pintor.

A presença de "Treze", de alguma maneira, opõe-se à raridade da presença e da palavra dos viciados como categoria fixa de sujeitos. Quanto mais inumano ele aparece, tanto mais sua fragilidade humana se insinua. Aos poucos, o vício vai se comprovando e recomprovando, mas, também aos poucos, o viciado adquire singularidade e transita entre várias identificações. "Treze" é gentil, não rouba, não é violento... Seria ele um viciado dócil, saído de uma categoria identificadora dos viciados violentos e alucinados e logo inserido em outra? Mas não seria também o que é consciente do vício ao mesmo tempo que a ele se entrega diante da câmera? 
A terceira cena testemunhal que descrevemos em preâmbulo é reveladora desse deslocamento do corpo e da própria identidade de "Treze". Já ao final do programa, e daquela jornada, ele consome as últimas pedras de crack do dia. Mas, na medida em que o programa e o dia avançam, e em que o personagem usa progressivamente mais droga, torna-se mais evidente a lucidez daquele sujeito a respeito da própria condição. À pergunta do jornalista sobre qual mundo preferiria, ou qual vida gostaria de levar, "Treze" responde com ironia: "- Posso fumar? Entendeu? Entendeu? Então já é!".

Se, em princípio, a resposta expressa uma não-consciência proveniente da total submissão à droga, o fato de advir sob a forma do deboche, de pergunta retórica, sem se render ao dispositivo interpretativo do interlocutor, ou mesmo às convenções e ao asseio da linguagem televisiva, ela dá mostras da capacidade que "Treze" possui não apenas para compreender a situação, mas principalmente para torná-la compreensível para outrem.

Através da cena testemunhal que $A$ Liga configura a partir da rotina de "Treze" $\mathrm{e}$ dos depoimentos do jornalista que o acompanha, nós, espectadores, somos colocados diante da manifestação daquela existência e do modo como aquele sujeito vai se constituindo entre a palavra da reportagem e a própria palavra, que se materializa no andar maneiro, na fala truncada, no olhar entorpecido e na surpreendente lucidez a respeito da própria condição marginal. Por que surpreendente? Talvez porque de um viciado não se espere mais do que ruído. A presença de "Treze" naquela cena testemunhal pressupõe uma encarnação do vivido e, ao mesmo tempo, produz "Treze" como um corpo sofredor.

Na réplica de "Treze" ao entrevistador, a afirmação de um comum cindido não aparece necessariamente sob a forma de um objeto em litígio, ou mesmo de um litígio argumentativo, mas estabelece-se um jogo compreensivo em torno da própria capacidade de compreender as condições e experiências. A sua fala escapa à modelização e padronização midiáticas sem, no entanto, deixar de ser "audível". Ante a suposta possibilidade de escolha entre dois mundos, a qual o jornalista pressupõe que o entrevistado não se dê conta, "Treze" pergunta se pode dar outro trago e se o jornalista entendeu.

A resposta indica menos a escolha entre as alternativas dadas por Rafinha Bastos do que a colocação em evidência de que, naquelas condições, só haveria uma alternativa possível. Entre um trago e outro no cigarro de crack, "Treze" mostra ao entrevistador que compreende bem a própria situação, e que é o jornalista quem precisa entender que já não se trata de escolhas entre alternativas viáveis.

A cena daquele testemunho parece revelar a difícil medida do comum que, a um só tempo, divide os sujeitos em mundos distintos ("Treze", o jornalista e também o espectador) e evidencia essa divisão que existe na própria coexistência dos mundos. Assim, embora configurado sob as regras da ordem discursiva midiática, o testemunho de "Treze" põe em cena seu corpo como marca do sofrimento, mas também como corpo falante - insinuando, de certo modo, uma "redistribuição dos corpos". "Treze", um homem viciado, sem existência nem palavra, aproveita um momento daquela encenação midiática para se mostrar, deixar-se aparecer e, no limite, falar e ser ouvido. 


\section{A abertura e o (des)encontro de mundos}

Ao se perguntar quando a política, para Rancière, acontece efetivamente, Tambakaki (2009) argumenta que ela não assume um caráter generalizado na obra do filósofo francês. A instauração de cenas polêmicas reveladoras de um comum cindido seria, na verdade, um episódio raro e historicamente marcado.

Embora ele nos apresente, por um lado, uma concepção estimulante e radical de política, uma política polêmica que potencialmente perturba e desloca modos estabelecidos de falar e fazer, por outro lado, ele anula essa significativa política quando simplesmente aquiesce a sua raridade (lbid., p. 105).

Em razão do poder disruptor dessa concepção de política, ganha força o argumento de que os episódios e as ações efetivamente políticas, ou seja, aquelas detentoras do poder de refigurar o sensível e de provocar uma abertura de mundo, concretizam-se em momentos históricos raros. Rancière (2011, p. 5; tradução nossa), no entanto, responde aos críticos que o acusam de reduzir a política a momentos excepcionais de "insurreição" dizendo que "há uma dinâmica histórica da política: uma história dos acontecimentos que irrompem o curso 'normal' do tempo, uma história dos acontecimentos, das inscrições e formas de subjetivação [...]".

Ainda assim, permanece desafiador enxergar em determinados fenômenos comunicativos como o testemunho midiático, um viés político nos termos de Rancière. Por outro lado, lançar mão desse quadro conceitual para entender determinados processos nos leva inevitavelmente ao questionamento sobre o potencial político de tais processos. Nesse sentido, por potencial político nos referimos especificamente à própria capacidade do testemunho para produzir cenas polêmicas e evidenciar um comum partilhado e uma separação evidente no ordenamento sensível dos corpos e falas.

O próprio Rancière (1996), no entanto, dá margem às aberturas de sentido provocadas por sua abordagem da política. Para o autor, "há política se a comunidade da capacidade argumentativa e da capacidade metafórica é, a qualquer hora e pela ação de qualquer um, passível de ocorrer" (ibid., p. 70). Se, por um lado, chama-se atenção para a possibilidade de criação de uma cena de dissenso a qualquer tempo e por qualquer um, deve-se sublinhar a definição de constituição do político como abertura de mundos singulares de comunidade, em que a igualdade a priori é questionada por meio de atos de palavra, da demonstração do dano fundador da política. Tal abertura pressupõe um deslocamento dos corpos e falas dos lugares que antes lhes eram reservados.

À luz dessa abordagem, a narrativa de $A$ Liga suscita ao menos dois problemas: o primeiro diz respeito à pressuposição de igualdade de condições. Na história de "Treze", a igualdade entre os sujeitos da cena, incluindo-se o espectador ao qual a cena é mostrada, é como que posta em suspensão, surgindo ao poucos em meio à diferença evidente. 
Por mais que se encene uma abertura à palavra de "Treze" no desenrolar daquela narrativa, as próprias condições físicas do personagem - após sucessivas sessões de consumo de crack - rompem qualquer equidade forjada pela trama entre o mundo de "Treze" e o nosso, por assim dizer. O seu corpo nunca se desloca completamente do papel de corpo sofredor.

Contudo, é pelo modo como ele toma a palavra em determinados momentos de lucidez registrados naquela história que se insinua um ligeiro deslocamento da fala e do sujeito do lugar que Ihe fora designado. O seu testemunho acaba por constituir um espaço em que a desigualdade pressuposta vai se invertendo na medida em que o personagem resiste, ainda que discretamente, à identificação que lhe é atribuída - e em que a lucidez que nos separa, como espectadores, de "Treze", é posta em xeque pela subjetivação do personagem.

O problema que, a nosso ver, oferece maior obstáculo ao potencial político da cena do testemunho configurada narrativamente por $A$ Liga está ligado à mudança de possíveis e ao poder refigurador da demonstração do dano, para usarmos os termos de Rancière.

Se, por um lado, podemos reivindicar àquela narrativa a constituição de uma medida comum a partir da coexistência, na cena do testemunho, de mundos tão distintos, o dano, para Rancière, não é resultante de uma concessão. O dano pressupõe exatamente que a palavra seja tomada por quem não tem palavra, e que uma ordem sensível seja ocupada por sujeitos que tradicionalmente estão à margem dela. Ganham ênfase, nesse contexto, a "tomada" da palavra e a "ocupação" do sensível, supondo o rompimento de uma ordem estabelecida, gesto dificilmente concebível no âmbito de uma ordem discursiva midiática.

Dar-se conta do efetivo lugar de "Treze" naquela história é, de certa forma, perceber que seu testemunho é por vezes tomado como palavra, e não apenas como barulho. O testemunho, assim, joga luz sobre sujeitos e experiências postos à margem da ordem consensual, do sistema de evidências sensíveis. Tal como disposta narrativamente, a palavra de "Treze" concilia dor, sofrimento e carência com uma persistente capacidade compreensiva do personagem. O seu testemunho nos coloca um paradoxo insolúvel: sob efeito do crack, até mesmo sua lucidez é questionável. O que permanece inegável é a afirmação daquela vulnerabilidade por meio da narrativa, o que reforça a contradição insuperável daquele mundo com o mundo do espectador.

\section{Considerações finais}

Diante do desafio de tirar consequências da abordagem política de Rancière para o testemunho midiático, resta-nos questionar se a própria experiência como espectadores daquele programa, de um ínfimo e roteirizado pedaço da vida de "Treze", já não dá provas suficientes da possibilidade de escutar uma fala perdida em meio à fala dominante, uma voz que é desejada pela ordem midiática pelas marcas de sofrimento, mas uma fala que não é respeitada.

Permanece, enfim, aberta a questão sobre o potencial político do testemunho midiático e de suas encenações. Porém, aproximando essas duas abordagens voltadas 
ao encontro de mundos dissensuais, esperamos ter jogado luz tanto sobre a relevância dessas cenas de testemunho como mecanismos capazes de tensionar uma ordem sensível, fazendo ver e ouvir corpos e falas que antes não eram percebidos ou ouvidos, quanto sobre o desafio de reivindicar um caráter político para processos comunicativos fortemente marcados pela roteirização e pelo uso de estratégias narrativas orientadas pela asserção de realidade própria do jornalismo.

Ao romper com modelos padronizados, lançando mão de outras lógicas narrativas como a imersão do repórter em determinadas experiências, o programa $A$ Liga acaba promovendo um encontro de mundos distintos, trazendo à tona vozes e sujeitos tradicionalmente alijados da ordem discursiva midiática - recordamo-nos, aqui, das recorrentes imagens das chamadas "cracolândias", em que os elementos da representação são corpos como objetos de palavra sem, no entanto, ter a palavra. O testemunho de "Treze", embora não consiga se desvencilhar completamente do lugar que lhe cabe de antemão naquela narrativa, de dor e sofrimento, revela-nos a (des) medida de nossos mundos: entendemo-nos, "Treze", o apresentador e o espectador, mas nos movemos em ordens discursivas e sensíveis profundamente diferentes.

Para Rancière (2005, p. 16), "é um recorte dos tempos e dos espaços, do visível e do invisível, da palavra e do ruído que define ao mesmo tempo o lugar e o que está em jogo na política como forma de experiência". E é esse mesmo recorte de tempos e espaços, do visível e do dizível, que torna o testemunho midiático enquanto fenômeno comunicativo um objeto importante para a análise a partir dessa abordagem da política. E o testemunho performado "na, pela e através" da narrativa de A Liga cria um terreno propício ao encontro entre um comum apaziguado e um comum polêmico e dissensual - a questão que persiste é saber se tal encontro se efetua, e se ele é capaz de rearranjar a ordem sensível que lhe precede.

\footnotetext{
Leandro Rodrigues Lage é doutorando vinculado ao Programa de Pós-Graduação em Comunicação Social da Universidade Federal de Minas Gerais (UFMG) e bolsista Capes. É mestre em Comunicação e Sociabilidades Contemporâneas pela UFMG e especialista em Comunicação: Imagens e Culturas Midiáticas pela UFMG. leandrorlage@gmail.com
}

\section{Referências}

ASHURI, T.; PINCHEVSKI, A. Witnessing as a field. In: FROSH, P; PINCHEVSKI, A. Media witnessing: Testimony in the age of mass communication. Basingstoke: Palgrave Macmillan, 2009, p.133-158.

ECO, U. (Org.). Viagem na irrealidade cotidiana. Rio de Janeiro: Nova Fronteira, 1984. 
FROSH, P. Telling Presences: Witnessing, Mass Media, and the Imagined Lives of Strangers In: FROSH, P; PINCHEVSKI, A. Media witnessing: Testimony in the Age of Mass Communication. Basingstoke: Palgrave Macmillan, 2009.

; PINCHEVSKI, A. Crisis-Readiness and Media Witnessing. The Communication Review, v. 12, n. 3, p. 295-304, 2009.

MARQUES, A. Comunicação, estética e política: a partilha do sensível promovida pelo dissenso, pela resistência e pela comunidade. Galáxia, São Paulo, n. 22, p. 25-39, dez. 2011.

PEETERS, J. D. Witnessing. In: FROSH, P; PINCHEVSKI, A. Media witnessing: Testimony in the age of mass communication. Basingstoke: Palgrave Macmillan, 2009, p. 23-41.

RANCIÈRE, J. Políticas da escrita. Rio de Janeiro: Ed. 34, 1995.

O desentendimento. São Paulo: Ed. 34, 1996.

Politique, identification, subjectivation. In:

Aux bords du politique. Paris: Gallimard, 2004, p. 112-125.

A partilha do sensível: estética e política. São Paulo: Ed. 34, 2005.

El espectador emancipado. Buenos Aires: Manantial, 2010.

The thinking of dissensus: politics and aesthetics. In: BOWMAN, P.; STAMP, R. Reading Rancière. London: Continuum, 2011, p. 1-17.

TAMBAKAKI, P. When Does Politics Happen? Parallax, v. 15, n. 3, p. 102-113, 2009.

Artigo recebido em julho

e aprovado em novembro de 2014. 